Article

\title{
Catalytic Performance of Lanthanum Vanadate Catalysts in Ammoxidation of 2-Methylpyrazine
}

\author{
Venkata N. Kalevaru ${ }^{1, *}$, Naresh Dhachapally ${ }^{2}$ and Andreas Martin ${ }^{1, *}$ \\ Received: 25 November 2015; Accepted: 7 January 2016; Published: 12 January 2016 \\ Academic Editor: Stuart H. Taylor \\ 1 Leibniz-Institut für Katalyse e.V. an der Universität Rostock, Albert-Einstein-Straße 29a, \\ 18059 Rostock, Germany \\ 2 SABIC Research and Technology Pvt. Ltd., Plot No. 81 to 85, Chikkadunnasandra, Sarjapura, \\ Bangalore-562125, India; naresh.dhachapally@sabic.com \\ * Correspondence: narayana.kalevaru@catalysis.de (V.N.K.); andreas.martin@catalysis.de (A.M.); \\ Tel.: +49-381-1281-284 (V.N.K.); +49-381-1281-246 (A.M.); Fax: +49-381-1281-51284 (V.N.K.); \\ +49-381-1281-51246 (A.M.)
}

\begin{abstract}
The influence of reaction conditions on the catalytic performance of lanthanum vanadate $\left(\mathrm{La}_{0.1} \mathrm{~V}_{0.9} \mathrm{O}_{x}\right)$ catalyst in the ammoxidation of 2-methylpyrazine (MP) to 2-cyanopyarazine (CP) has been investigated. This novel catalytic material exhibited remarkably good performance with very high space-time-yields (STY) of CP. The reaction parameters such as the effect of temperature, gas hourly space velocity (GHSV) and all other reaction variables (e.g., $\mathrm{NH}_{3}$, air, and MP feed rates) on the catalytic performance were explored and optimized. For example, an increase in MP feed rate from 2 to $>16 \mathrm{mmol} / \mathrm{h}$ led to decreased conversion of MP but increased the STY of CP significantly. Optimal performance was achieved when the reaction temperature was $420^{\circ} \mathrm{C}$ and the molar ratio of 2-MP, ammonia, air, $\mathrm{H}_{2} \mathrm{O}$ and $\mathrm{N}_{2}$ in the feed gas was set to 1:7:26:13:22. Under these optimal reaction conditions, the catalyst showed a MP conversion of $\sim 100 \%$, CP selectivity of $86 \%$, and STY of $>500 \mathrm{~g}_{\mathrm{CP}} /\left(\mathrm{kg}_{\mathrm{cat}} \cdot \mathrm{h}\right)$. On the other hand, the formation of pyrazine (Py) as a by-product was found to be high when the $\mathrm{NH}_{3}: \mathrm{MP}$ ratio was lower at increased contact time. This suggests possible differences in the reaction mechanism pathways with respect to feed composition over $\mathrm{La}_{0.1} \mathrm{~V}_{0.9} \mathrm{O}_{x}$ catalysts.
\end{abstract}

Keywords: 2-methylpyrazine; 2-cyanopyrazine; ammoxidation; lanthanum vanadate; reaction parameters

\section{Introduction}

The heterogeneously catalyzed ammoxidation is a selective oxidation of olefins and methyl aromatics (or hetero aromatics), respectively, that is carried out in the presence of ammonia, leading to commercially valuable nitriles [1,2]. Outstanding examples are the reaction of propene to acrylonitrile and the conversion of $m$ - and $p$-xylene to isoterephthalic and terephthalic dinitrile, respectively [3,4]. The production of acrylonitrile has global importance; about seven million tons were produced worldwide in 2015 with $c a$. $2.5 \%$ annual consumption growth rate for the next five years. To be brief, the reaction follows a Mars-van Krevelen mechanism, i.e., nucleophilic oxygen is introduced into an activated allyl or benzyl species forming an oxygen-containing intermediate $[5,6]$. Such an intermediate interacts with ammonia adsorbed on the catalyst surface, forming an imine that is further dehydrated to a nitrile [7]. As mentioned above, olefins or methyl aromatics and hetero aromatics can be used as feed; in this regard, the ammoxidation of 2-methylpyrazine (MP) belongs to this group of reactions. It allows the manufacture of 2-cyanopyrazine (CP) in a single step and is an industrially important reaction as well. In detail, $\mathrm{CP}$ is an intermediate compound to synthesize pyrazinamide (PyA) that is globally used as an effective anti-tubercular drug [8]. 
A variety of transition metal-containing catalyst systems, on supports or bulk materials as well, have been applied for ammoxidation reactions in general [1,3], MP in particular, e.g., $[1,9,10]$. For instance, vanadium phosphate-based solids [11,12], $\mathrm{FePO}_{4}$ [13], MoVPO [14], hetero polyacids [15,16], $\mathrm{V}_{2} \mathrm{O}_{5} / \mathrm{TiO}_{2}[9,10], \mathrm{VMoO}_{x}$ [17], AuNPs [18] or SbVMn mixed oxides $[19,20]$ are described catalyst systems for the title reaction. The conversion is generally carried out in the temperature range of $360-420{ }^{\circ} \mathrm{C}$ under ambient pressure. Recently, we have studied the properties of various metal vanadates (e.g., $\mathrm{AlVO}_{4}, \mathrm{FeVO}_{4}, \mathrm{CrVO}_{4}, \mathrm{NbVO}_{5}, \mathrm{LaVO}_{4}$, and $\mathrm{BiVO}_{4}$ ) as a new class of catalytic active materials. Some of these solids revealed improved yields for $\mathrm{CP}[21,22]$. Besides $\mathrm{CP}$, pyrazine (Py), pyrazinamide (PyA), $\mathrm{CO}$ and $\mathrm{CO}_{2}$ were observed as by-products. Pyrazine formation is supposed to occur from the demethylation of MP that might happen as a consecutive step after methyl group activation; the hetero aromatic molecule is activated by hydride abstraction, leading to a methylene-like species as we found out recently by in situ- FTIR spectroscopy of the ammoxidation of toluene to benzonitrile $[7,23]$. Here, a benzaldehyde-like intermediate was formed which might react toward an imine in the presence of ammonia; the nitrile is formed afterwards by oxidative dehydration. Otherwise, benzene was also seen in this case as a result of demethylation. Pyrazinamide formation is expected from the hydrolysis of $\mathrm{CP}$. $\mathrm{CO}$ and $\mathrm{CO}_{2}$ result from unavoidable total oxidation which also generates water (Scheme 1).

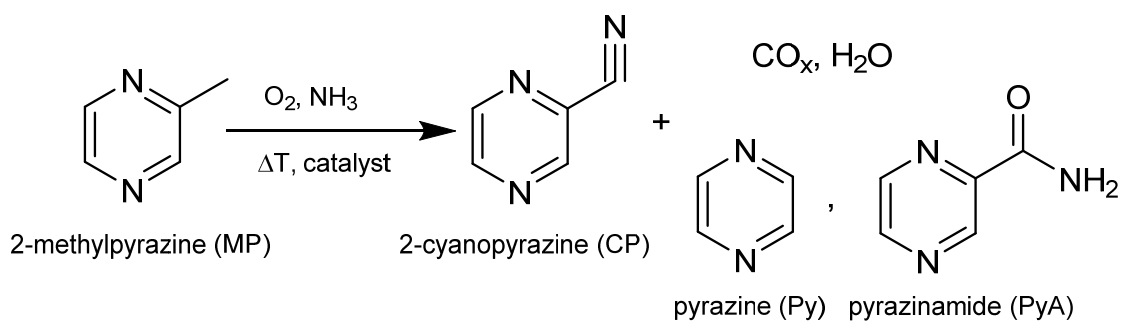

Scheme 1. Reaction scheme for ammoxidation of MP leading to $\mathrm{CP}$, other hetero aromatic by-products and products of total oxidation as well.

It has been observed previously that the nature of metal in metal vanadate has shown clear influence on the catalytic performance [21,24]. Very recently, the near-surface region and the outermost surface layer of such vanadates were studied by X-ray Photoelectron Spectroscopy (XPS) and Low-Energy Ion Scattering (LEIS) [25]. This technique clearly showed how important stable vanadium-enriched or pure vanadia outermost surface layers are for a selective catalyst requiring an optimum electron and oxygen $\left(\mathrm{O}^{2-}\right)$ transport in the surface layers for best performance. In contrast, mixed oxide-containing outermost layers are detrimental for the catalytic behavior. Among all, $\mathrm{NbVO}_{5}$ and $\mathrm{LaVO}_{4}$ solids showed superior performance; however, under optimized $\mathrm{Nb}: \mathrm{V}[24]$ and $\mathrm{La}: \mathrm{V}$ ratios, respectively, the $\mathrm{La}_{0.1} \mathrm{~V}_{0.9} \mathrm{O}_{x}$ solid has displayed the best performance [26].

Therefore, this latter catalyst composition was investigated further with respect to optimizing product yield and selectivity. Another significant goal was the increase of the space-time-yield as an important measure for industrial applicability. Therefore, most of the catalytic tests were carried out at, more or less, complete MP conversion. In this contribution, we describe the optimization of the reaction parameters to reach the above-mentioned aims.

\section{Results and Discussion}

In our previous investigations, we have examined the effect of various metals $(\mathrm{Al}, \mathrm{Fe}, \mathrm{Cr}, \mathrm{Nb}$, $\mathrm{La}, \mathrm{Bi}$ ) in metal vanadate (MVs) catalysts (e.g., $\mathrm{AlVO}_{4}, \mathrm{FeVO}_{4}, \mathrm{CrVO}_{4}, \mathrm{NbVO}_{5}, \mathrm{LaVO}_{4}$, and $\mathrm{BiVO}_{4}$ ) with constant metal-to-vanadium molar ratio (i.e., 1:1) and tested their potentiality towards the ammoxidation of MP to CP [21,22]. We have also previously explored the effect of reaction temperature on the catalytic performance of MP to CP for all solids mentioned above [21]. The conversion of MP (X-MP) reached almost $100 \%$ over most of the MVs when the reaction temperature window was tuned 
in the range from 320 to $460{ }^{\circ} \mathrm{C}$ in every case except $\mathrm{BiVO}_{4}$, which has shown only ca. $75 \%$ conversion of MP at $>440{ }^{\circ} \mathrm{C}$ [21]. In contrast, the total X-MP is already reached at much lower temperature (i.e., $340{ }^{\circ} \mathrm{C}$ ) over the $\mathrm{AlVO}_{4}$ solid [21]. The catalyst activity increases in the following order: $\mathrm{BiVO}_{4}<\mathrm{LaVO}_{4}<\mathrm{NbVO}_{5}<\mathrm{CrVO}_{4} \approx \mathrm{FeVO}_{4}<\mathrm{AlVO}_{4}$. The selectivity to CP (S-CP), in general, is found to increase to a peak temperature and then decreases with a further rise in temperature. At lower reaction temperatures, mainly pyrazinamide is formed as an intermediate whereas at higher reaction temperatures, pyrazine and carbon oxides are the dominant by-products formed. Only in case of the $\mathrm{AlVO}_{4}$ solid the S-CP decreases steadily with an increase in reaction temperature. Further details on the temperature dependency of the conversion of MP and product yields were already reported earlier [21,26]. On the other hand, the $\mathrm{LaVO}_{4}$ solid under optimized La:V ratio exhibited the best performance and seemed to be a good balance with respect to conversion and selectivity [21,26]. Nevertheless, this catalyst requires a relatively high reaction temperature $\left(420{ }^{\circ} \mathrm{C}\right)$ to obtain $100 \%$ conversion of MP. Despite such a high reaction temperature, there is no considerable loss of selectivity towards $\mathrm{CP}$, which is indeed remarkable.

In general, the nature of the metal in the synthesized metal vanadate catalysts and its distribution is a crucial parameter, which appears to control both the conversion of MP and the distribution of products. From the above results, it seems that orthovanadate materials exhibit a high selectivity of the desired products when the $\mathrm{VO}_{4}$ units are separated from each other by $\mathrm{MO}_{x}$ units and all the lattice oxygen ions are involved in the solid bridge $(\mathrm{M}-\mathrm{O}-\mathrm{V})$ between $\mathrm{V}^{5+}$ and $\mathrm{M}^{\mathrm{n}+}$ ions. The absence of $\mathrm{V}^{5+}-\mathrm{O}-\mathrm{V}^{5+}$ bonds in which the lattice oxygen can be readily removed due to the high reducibility of the two $\mathrm{V}^{5+}$ ions is the reason for the low combustion (total oxidation) activity of the metal vanadates compared to $\mathrm{V}_{2} \mathrm{O}_{5}$. A similar situation can be expected from the present $\mathrm{LaVO}_{4}$ and $\mathrm{BiVO}_{4}$ catalysts due to the formation of well crystalline pure metal vanadate phases and, hence, the low combustion activity (i.e., high selectivity of $\mathrm{CP}$ ). On the other hand, the reverse trend is observed in the case of $\mathrm{AlVO}_{4}$ catalysts, where the free crystalline $\mathrm{V}_{2} \mathrm{O}_{5}$ phase is present in major proportion.

The $\mathrm{LaVO}_{4}$ catalyst system was selected for further variation of the $\mathrm{V}$ : ratio due to its relatively superior catalytic performance in the ammoxidation of MP. Therefore, different $\mathrm{La}_{a} \mathrm{~V}_{b} \mathrm{O}_{x}$ ( $a=0$ to 1.0 and $b=1.0$ to 0 ) solids with varying La:V ratios were prepared and tested; several solid characterization results with respect to surface, electronic and phase properties can be found elsewhere $[21,22,25]$. Thus, the optimized combination of La and $\mathrm{V}$ ratios remarkably improved the performance. The conversion of MP is observed to increase continuously with an increase in the vanadium content and reached almost $100 \%$ conversion on $\mathrm{La}_{0.1} \mathrm{~V}_{0.9} \mathrm{O}_{x}$ catalysts using the reaction conditions given below, where the yield of $\mathrm{CP}$ has also been observed to be high. However, further increase in the vanadium content causes a decrease in the yield of $C P$. Among different $\mathrm{La}_{a} \mathrm{~V}_{b} \mathrm{O}_{x}$ solids studied, the catalyst with a La:V molar ratio of 0.1:0.9 (i.e., $\mathrm{La}_{0.1} \mathrm{~V}_{0.9} \mathrm{O}_{x}$ ) exhibited the best performance. The best yield of $\mathrm{CP}$ is found to be $>85 \%$ at almost total conversion of MP $\left(T=420{ }^{\circ} \mathrm{C}, \mathrm{GHSV}=11883 \mathrm{~h}^{-1}, \mathrm{MP}_{\mathrm{NH}}: \mathrm{Nir}_{3}: \mathrm{H}_{2} \mathrm{O}: \mathrm{N}_{2}=\right.$ 1:7:26:13:22). Additionally, the best space-time-yield (STY) of CP of over $500 \mathrm{~g}_{\mathrm{CP}} /\left(\mathrm{kg}_{\text {cat }} \cdot \mathrm{h}\right)$ was obtained successfully for the first time. This is the highest value obtained so far compared to all other existing literature reports on this reaction. Further details on the effect of varying the lanthanum-to-vanadium mole ratio and the dependency of the conversion of MP and product yields can be found elsewhere [26].

Taking into consideration this best composition and the best performance of the $\mathrm{La}_{0.1} \mathrm{~V}_{0.9} \mathrm{O}_{x}$ catalyst, we have further optimized various other reaction variables such as the concentration of MP, ammonia, air, and $\mathrm{H}_{2} \mathrm{O}$ vapor in the reactant feed mixture. Besides, attempts were also made to check the effect of contact time as well as the time-on-stream behavior of the best catalyst system. By studying these reaction variables, quite interesting results were observed, which are discussed in detail in the following sections.

At first, the effect of MP concentration in the feed mixture was explored and the results are presented in Figure 1. With an increase in the MP feed rate from 3.0 to $16 \mathrm{mmol}_{\mathrm{MP}} / \mathrm{h}$, the conversion is decreased from $100 \%$ to $88 \%$ while the yield of $\mathrm{CP}$ is increased up to $6.0 \mathrm{mmol}_{\mathrm{MP}} / \mathrm{h}$ feed and then decreased with a further increase in the MP concentration. At lower MP content $\left(3.0 \mathrm{mmol}_{\mathrm{MP}} / \mathrm{h}\right)$, 
the by-product Py is received in yields up to $10 \%-15 \%$. Py formation is due to demethylation as already mentioned above. At higher MP content, the Py yield dropped but the amide (PyA) and other by-product (carbon oxides mainly) concentrations are raised. The increase in carbon oxide formation is caused by an expanding hot-spot region in the catalyst bed because ammoxidation is a highly exothermic reaction. This process is pushed due to the increased MP feed rate. In addition, much more water is produced by total oxidation, leading to an increase in PyA formation, too. However, the very interesting result is that extremely high space-time-yield of CP (i.e., $\left.>900 \mathrm{~g}_{\mathrm{CP}} /\left(\mathrm{kg}_{\text {cat }} \cdot \mathrm{h}\right)\right)$ could be achieved for the first time at higher MP content in the feed despite a decrease in the conversion of MP. It should be noted that the total flow of the feed mixture is kept constant all the time by adjusting the diluent gas flow (i.e., $\mathrm{N}_{2}$ flow) so that a constant GHSV is maintained.

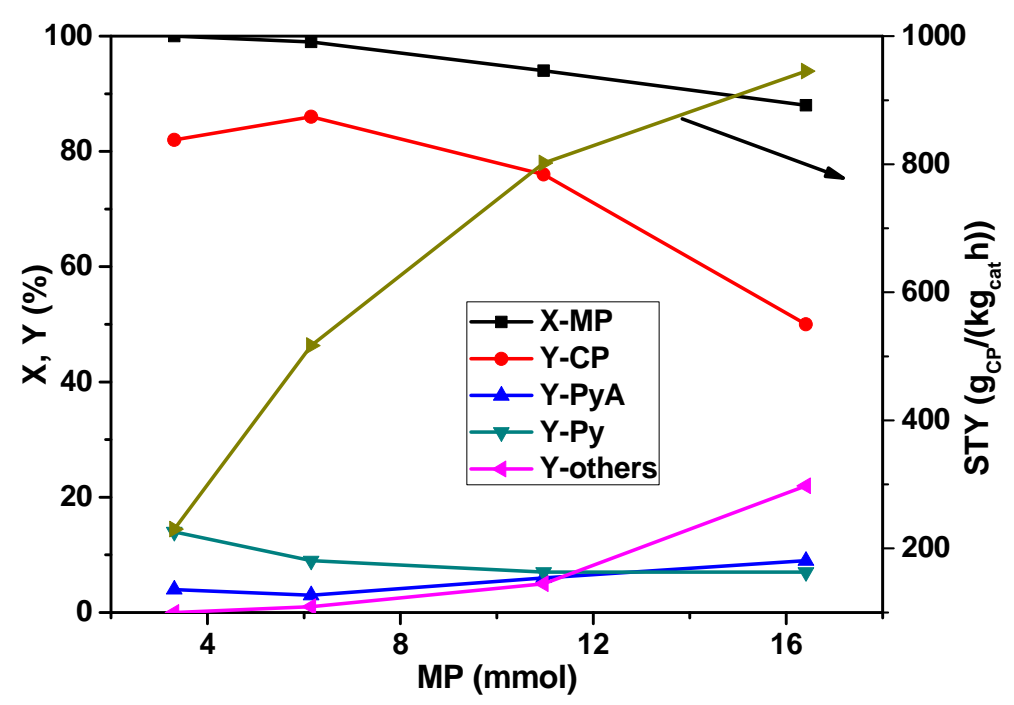

Figure 1. Effect of 2-methylpyrazine (MP) feed rate on the conversion of MP and product yields in the ammoxidation reaction over $\mathrm{La}_{0.1} \mathrm{~V}_{0.9} \mathrm{O}_{x}$ solid (reaction conditions: $T=420{ }^{\circ} \mathrm{C}$; feed molar ratio: $\mathrm{NH}_{3}:$ air: $\mathrm{H}_{2} \mathrm{O}=7: 26: 13 ; \mathrm{GHSV}=11883 \mathrm{~h}^{-1} ; \tau=0.3 \mathrm{~s}$; catalyst weight $=1 \mathrm{~g} ; \mathrm{CP}=2$-cyanopyrazine, PyA = pyrazinamide, Py = pyrazine, others = carbon oxides $)$.

The dependency of MP conversion and product yield on the concentration of $\mathrm{NH}_{3}$ in the feed mixture is illustrated in Figure 2. The conversion of MP remained almost constant irrespective of the ammonia flow in the feed; however, the product selectivities have been dramatically affected. The yield of $\mathrm{CP}$ is increased from 50 to $>80 \%$ up to a $\mathrm{NH}_{3}$ flow rate of $42 \mathrm{mmol}_{\mathrm{NH} 3} / \mathrm{h}$ and then decreased with the further increase of the ammonia proportion. Obviously, high ammonia concentration leads to an occupation of reaction sites; as a consequence, MP conversion drops. At lower ammonia content, the by-products such as Py and carbon oxides are more than $20 \%$, which are, however, decreased with the increase of the ammonia flow rate. The high yields of Py and carbon oxides are expected mainly due to the demethylation of MP easily running at low ammonia availability and simultaneous total oxidation reactions preferentially proceeding with oxygen-containing intermediates. From this study, it appears that $42 \mathrm{mmol}_{\mathrm{NH} 3} / \mathrm{h}$ flow of $\mathrm{NH}_{3}$ seemed to be optimum for the improved yield of $\mathrm{CP}$.

The influence of air (oxygen) on the product distribution in the ammoxidation of MP is summarized in Figure 3. It has been noticed that the air flow has a clear effect on the catalyst performance. Even though the conversion of MP remained constant at $\sim 100 \%$ with increasing the air content, the yields and selectivities of products, respectively, are considerably varied. The yield of $\mathrm{CP}$ increased from $62 \%$ to $85 \%$ up to an air flow rate of $160 \mathrm{mmol}_{\text {air }} / \mathrm{h}$ and then decreased with the further increase of air content. At low air contents, the formation of Py is more likely due to possible demethylation of MP. Higher air contents lead to an increasing total oxidation. This series reveals that ca. $160 \mathrm{mmol}_{\text {air }} / \mathrm{h}$ is optimum for obtaining enhanced yields of CP. 


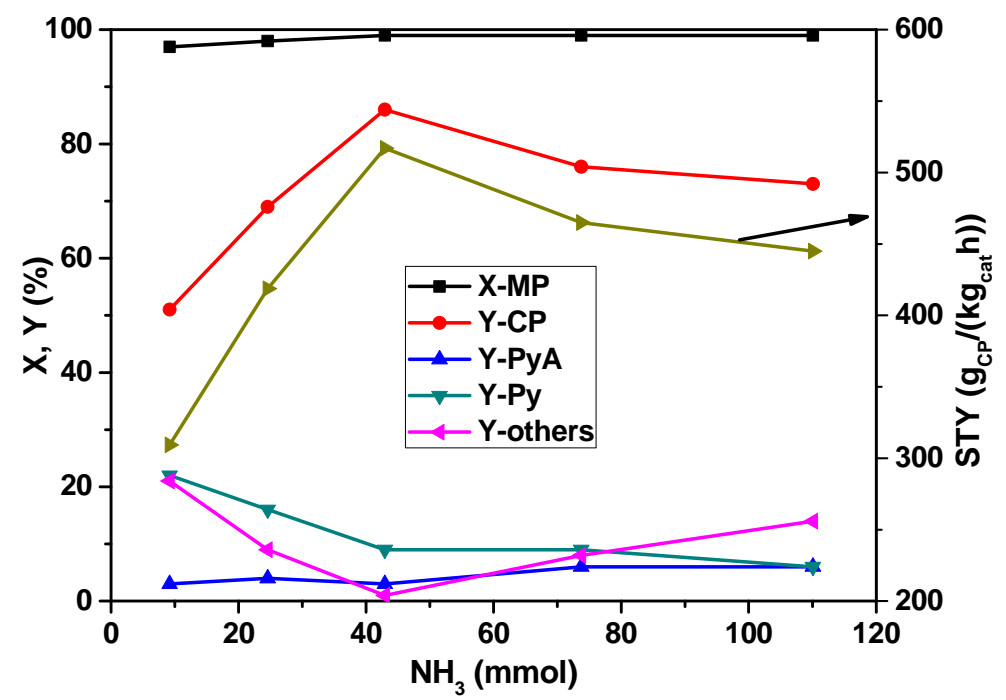

Figure 2. Impact of ammonia flow rate on X-MP and product yields (reaction conditions: $\mathrm{T}=420^{\circ} \mathrm{C}$; feed molar ratio: MP:air: $\mathrm{H}_{2} \mathrm{O}=1: 26: 13$; GHSV $=11883 \mathrm{~h}^{-1} ; \tau=0.3 \mathrm{~s}$; catalyst weight $=1 \mathrm{~g}$; MP flow: $6.2 \mathrm{mmol} / \mathrm{h})$.

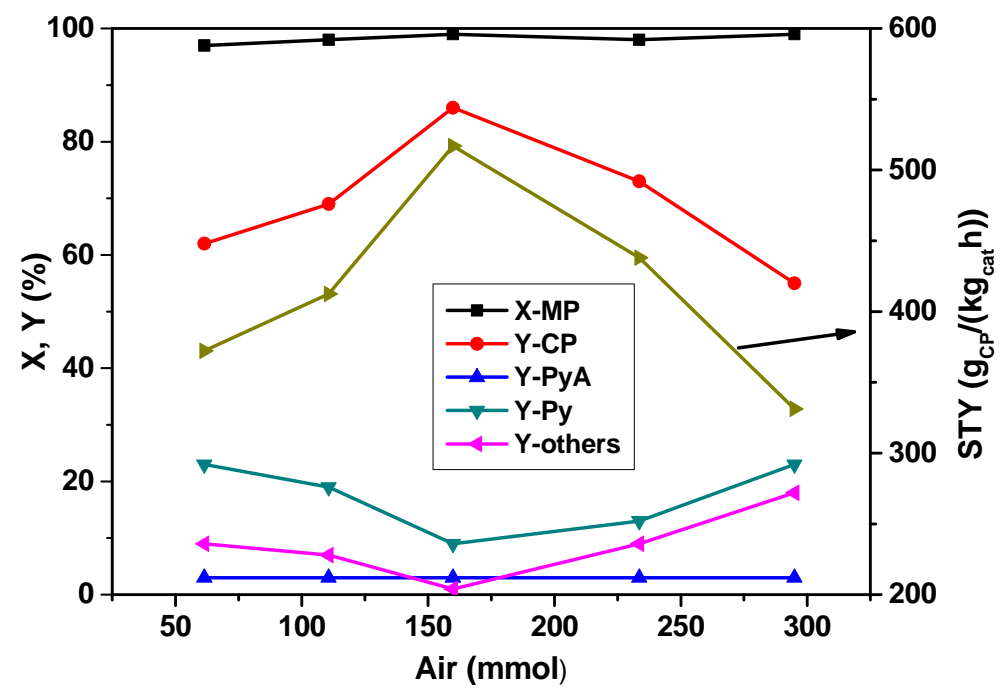

Figure 3. Effect of air feed proportion on $\mathrm{X}-\mathrm{MP}$ and product yields (reaction conditions: $\mathrm{T}=420{ }^{\circ} \mathrm{C}$; feed molar ratio: $\mathrm{MP}: \mathrm{NH}_{3}: \mathrm{H}_{2} \mathrm{O}=1: 7: 13 ; \mathrm{GHSV}=11883 \mathrm{~h}^{-1} ; \tau=0.3 \mathrm{~s}$; catalyst weight $=1 \mathrm{~g}$; MP flow: $6.2 \mathrm{mmol} / \mathrm{h}$ ).

Furthermore, the influence of the water vapor feed proportion on the conversion of MP and the product distribution in the ammoxidation of MP was explored and is depicted in Figure 4. It is obvious from the figure that in the absence of water vapor in the feed mixture, Py is the main product at complete MP conversion. Only with additionally feeding water vapor $\mathrm{CP}$ becomes the main product and the product distribution turns dramatically. The increased water content beyond $80 \mathrm{mmol} / \mathrm{h}$ has not shown considerable influence on the conversion of MP, but the yield of CP increased from 40 to $\sim 85 \%$ up to $80 \mathrm{mmol} / \mathrm{h}$ water vapor and then remained almost constant beyond this value. However, the opposite trend is observed for Py formation. At lower water content $(<50 \mathrm{mmol} / \mathrm{h})$, Py formation is appreciably high (53\%), which is then decreased drastically to $9 \%$ with an increase in water content to $80 \mathrm{mmol} / \mathrm{h}$ and then remains constant beyond that. It is known that the presence of water vapor is essential to facilitate the easy desorption of the products and also to control the exothermicity of the 
reaction. This study implies that a water vapor flow rate of $\sim 80 \mathrm{mmol} / \mathrm{h}$ seems to be optimum for the enhanced yield of $\mathrm{CP}$.



Figure 4. Influence of water vapor content on X-MP and product yields (reaction conditions: $T=420{ }^{\circ} \mathrm{C}$; feed molar ratio: $\mathrm{MP}: \mathrm{NH}_{3}$ :air $=1: 7: 26 ; \mathrm{GHSV}=11883 \mathrm{~h}^{-1} ; \tau=0.3 \mathrm{~s}$; catalyst weight $=1 \mathrm{~g}$; MP flow: $6.2 \mathrm{mmol} / \mathrm{h})$.

In subsequent studies, the influence of the space velocity on the MP ammoxidation was investigated by varying the amount of the catalyst in the range from 0.4 to $2.4 \mathrm{~g}$ and keeping the total flow rate of the feed mixture constant. Figure 5 depicts the changes in the conversion of MP and the yields of the reaction products as a function of space velocity under steady-state conditions. With the increase in GHSV, the conversion of MP remained constant up to $11883 \mathrm{~h}^{-1}$ and then decreased with a further increase. However, the yield of CP is increased from $47 \%$ to $85 \%$ up to $11883 \mathrm{~h}^{-1} \mathrm{GHSV}$, and then decreased with a further increase. At low GHSV, a by-product such as pyrazine formation is increased, but it is, however, decreased with the increase of GHSV beyond $11883 \mathrm{~h}^{-1}$. On the whole, a GHSV of $11883 \mathrm{~h}^{-1}$ appears to be optimum for better performance.

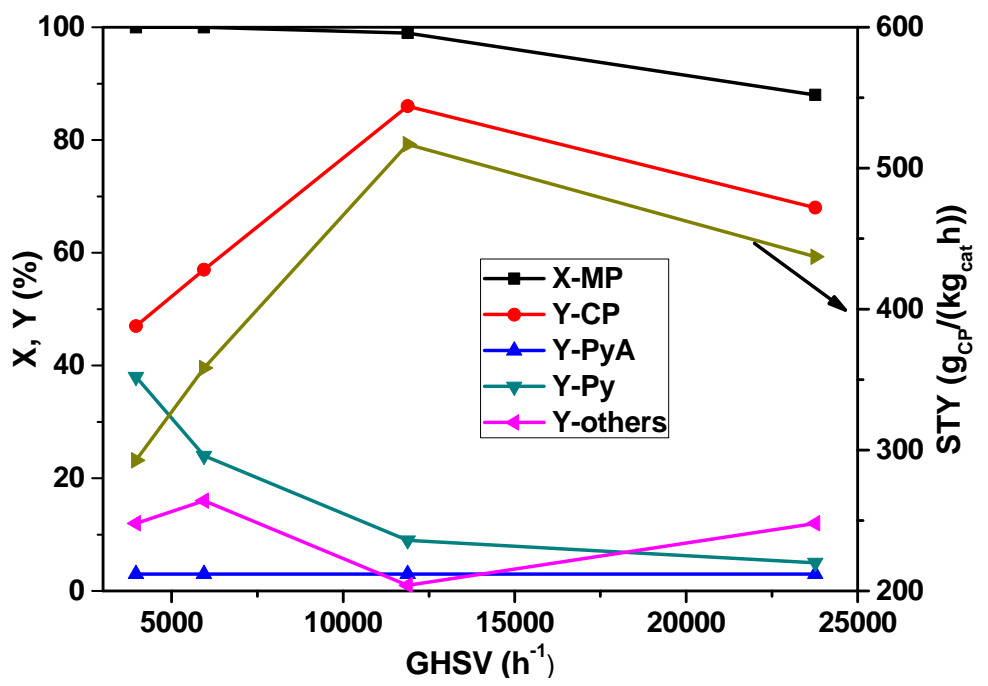

Figure 5. Effect of increasing GHSV on X-MP and product yields (reaction conditions: $\mathrm{T}=420^{\circ} \mathrm{C}$; feed molar ratio: $\mathrm{MP}: \mathrm{NH}_{3}:$ air: $\mathrm{H}_{2} \mathrm{O}: \mathrm{N}_{2}=1: 7: 26: 13: 22 ; \tau=0.91-0.15 \mathrm{~s}$; catalyst weight $=0.4-2.4 \mathrm{~g}$ ). 
Finally, the time-on-stream behavior of the catalyst under study using the best parameters set was also investigated and is presented in Figure 6. It is evident from the figure that the novel $\mathrm{La}_{0.1} \mathrm{~V}_{0.9} \mathrm{O}_{x}$ catalyst has exhibited an acceptably good stability over a period of $10 \mathrm{~h}$ as tested in our laboratory. The conversion of MP remained more or less constant at 100\% throughout the testing period, and interestingly, the yield of $\mathrm{CP}$ appears to increase slightly with time. From the above results we can conclude that this catalyst composition is more resistant towards deactivation by coke formation and/or agglomeration by sintering of $\mathrm{VO}_{x}$ and/or $\mathrm{LaVO}_{x}$ species compared to other $\mathrm{VO}_{x}$-containing catalyst systems. In general, sintering leads to larger particles showing a decrease in conversion due to reduced active surface area and sometimes changes in product selectivity due to alteration in bulk properties such as increasing oxygen $\left(\mathrm{O}^{2-}\right)$ and / or electron transport. Hence, this particular catalyst composition has good potential for its operation on large-scale production of $\mathrm{CP}$.

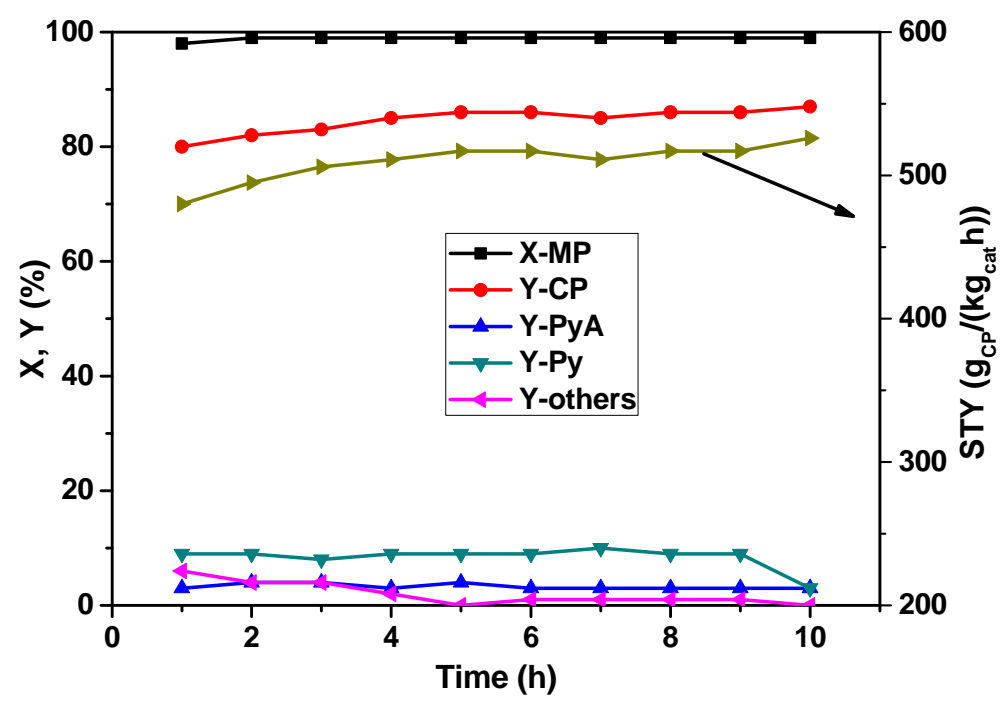

Figure 6. Time-on-stream behavior of $\mathrm{La}_{0.1} \mathrm{~V}_{0.9} \mathrm{O}_{x}$ solid in the MP ammoxidation reaction (reaction conditions: $\mathrm{T}=420{ }^{\circ} \mathrm{C}$; feed molar ratio: $\mathrm{MP}: \mathrm{NH}_{3}:$ air: $\mathrm{H}_{2} \mathrm{O}: \mathrm{N}_{2}=1: 7: 26: 13: 22 ; \mathrm{GHSV}=11883 \mathrm{~h}^{-1}$; $\tau=0.3 \mathrm{~s} ;$ MP flow: $6.2 \mathrm{mmol} / \mathrm{h})$.

\section{Experimental Section}

$\mathrm{La}_{0.1} \mathrm{~V}_{0.9} \mathrm{O}_{x}$ catalyst with La: $\mathrm{V}$ molar ratio of 0.1:0.9 was prepared by citric acid decomposition method $[21,26]$. The preparation of this particular bulk metal vanadate involves two steps. The first step deals with the preparation of lanthanum metal solution. The requisite quantity of lanthanum nitrate hexahydrate $\left(\mathrm{La}\left(\mathrm{NO}_{3}\right)_{3} \cdot 6 \mathrm{H}_{2} \mathrm{O}\right)$ salt was dissolved in appropriate amount of distilled water, to which citric acid (CA) in desired amount was added (molar ratio of La:CA $=3: 1$ ) and then the mixture was stirred at room temperature until clear solution is obtained. The second step involves the preparation of vanadium solution using $\mathrm{NH}_{4} \mathrm{VO}_{3}(\mathrm{AMV}$ ) as a precursor for vanadium. The required amount of AMV was taken in distilled water and suitable amount of oxalic acid (OA) was added to it (molar ratio of $\mathrm{AMV}: \mathrm{OA}=1: 1.5$ ). The latter was then heated to $60^{\circ} \mathrm{C}$ on a hot plate and then kept at the same temperature for 10 minutes under stirring. Afterwards, the above V-OA solution was added drop-wise to the La-CA acid solution at $60^{\circ} \mathrm{C}$ with constant stirring. After complete addition, the mixture was heated to $80^{\circ} \mathrm{C}$ and then slowly evaporated to dryness on a hotplate. The solid thus obtained was further dried at $110^{\circ} \mathrm{C}$ for $16 \mathrm{~h}$ in an oven. Finally, the sample was calcined at $600^{\circ} \mathrm{C}$ for $15 \mathrm{~h}$ in air $(4 \mathrm{~L} / \mathrm{h})$. All used chemicals were obtained from Sigma-Aldrich (Sigma-Aldrich Chemie $\mathrm{GmbH}$, München, Germany).

This particular $\mathrm{La}_{0.1} \mathrm{~V}_{0.9} \mathrm{O}_{x}$ catalyst exhibited a rather low surface area of $<5 \mathrm{~m}^{2} / \mathrm{g}$ as determined by nitrogen adsorption using Quantachrome NOVA 4200e instrument (QUANTACHROME GmbH \& Co. KG, Odelzhausen, Germany). The surface area did not change much in the spent sample. 
Catalytic tests were carried out in a continuous tubular fixed bed stainless steel reactor (id $=10 \mathrm{~mm}$ ) that is heated in an electrical furnace at a temperature of $420^{\circ} \mathrm{C}$ and at ambient pressure. Reactant gases such as air and ammonia were metered by using mass flow controllers (Bronkhorst Deutschland Nord $\mathrm{GmbH}$, Kamen, Germany); liquid feeds (MP and $\mathrm{H}_{2} \mathrm{O}$ ) were dosed by HPLC pumps (Shimadzu Deutschland $\mathrm{GmbH}$, Duisburg, Germany). $\mathrm{N}_{2}$ gas was used additionally as a diluent to maintain the total flow constant and thus the constant gas hourly space velocity (GHSV). Liquids were mixed with gases in a quartz-wool filled preheater ensuring vaporization of liquids and complete mixing of feed components. Two thermocouples were positioned; one at the center of the catalyst bed to indicate reaction temperature and the other one was attached to furnace through temperature indicator-cum-controller to monitor the temperature of the reaction. One gram of catalyst particles $(d=1-1.25 \mathrm{~mm})$ was loaded in the reactor in between quartz wool plugs. The bottom and top parts of catalyst bed were filled with corundum in order to reduce the dead volume and also for better heat transfer. The reaction was then carried out under suitable reaction conditions. The reaction products were collected in an ice-cooled trap for every half an hour and analyzed by GC (Shimadzu Deutschland $\mathrm{GmbH}$, Duisburg, Germany) equipped with FID. Carbon oxides were analyzed by on-line gas analyses using a methanizer and FID. MP conversion and product yields were directly obtained from the GC data; product selectivity if noted was easily available by dividing product yield by MP conversion. The carbon balance was calculated based on MP concentration at the inlet of the reactor; it always showed values between $95 \%$ and $100 \%$. The calculation of conversion (X-MP), yield (Y-CP), selectivity (S-CP) and space-time-yield (STY-CP) based on MP are illustrated below:

$$
\begin{gathered}
X-M P=\frac{c_{M P, 0}-c_{M P}}{c_{M P, 0}} \\
Y-C P=\frac{c_{C P}}{c_{M P, 0}} \\
S-C P=\frac{c_{C P}}{c_{M P, 0-C_{M P}}} \\
S T Y-C P=\frac{C P \text { formed }\left(\frac{g}{h}\right)}{\text { catalyst amount }(\mathrm{kg})}
\end{gathered}
$$

The yield and selectivity of the by-products pyrazinamide and pyrazine as well as carbon oxides were calculated in the same way.

\section{Conclusions}

It can be concluded that the $\mathrm{La}_{0.1} \mathrm{~V}_{0.9} \mathrm{O}_{x}$ catalyst has exhibited a much-improved performance compared to the state-of-the-art. Results revealed strong evidence that the reaction variables have shown a clear influence on the conversion of MP as well as the product distribution. By the application of the currently developed catalyst composition, almost $100 \%$ conversion of $\mathrm{MP},>85 \%$ yield of $\mathrm{CP}$, along with extremely high space-time-yields, could be successfully achieved.

Acknowledgments: Thanks are due to Karin Struve of LIKAT for experimental help.

Author Contributions: A.M. and V.N.K. conceived and designed the experiments; N.D. performed the experiments; V.N.K. and N.D. analyzed the data; V.N.K. and A.M.wrote the paper.

Conflicts of Interest: The authors declare no conflict of interest.

\section{References}

1. Martin, A.; Kalevaru, V.N. Heterogeneously catalyzed ammoxidation-A valuable tool for one-step synthesis of nitriles. Chem CatChem 2010, 2, 1504-1522. [CrossRef]

2. Grasselli, R.K.; Burrington, J.D. Selective oxidation and ammoxidation of propylene by heterogeneous catalysis. Adv. Catal. 1981, 30, 133-163. 
3. Holmberg, J.; Grasselli, R.K.; Andersson, A. Catalytic behaviour of M1, M2, and M1/M2 physical mixtures of the Mo-V-Nb-Te-oxide system in propane and propene ammoxidation. Appl. Catal. A 2004, 270, 121-134. [CrossRef]

4. Grasselli, R.K. Advances and future trends in selective oxidation and ammoxidation catalysis. Catal. Today 1999, 49, 141-153. [CrossRef]

5. Mars, P.; van Krevelen, D.W. Oxidations carried out by means of vanadium oxide catalysts. Chem. Eng. Sci. 1954, 3, 41-59. [CrossRef]

6. Doornkamp, C.; Ponec, V. The universal character of the Mars and Van Krevelen mechanism. J. Mol. Catal. A 2000, 162, 19-32. [CrossRef]

7. Zhang, Y.; Martin, A.; Berndt, H.; Lücke, B.; Meisel, M. FTIR investigation of surface intermediates formed during the ammoxidation of toluene over vanadyl pyrophosphate. J. Mol. Catal. A 1997, 118, 205-214. [CrossRef]

8. Kagarlitskii, A.D.; Krichevskii, L.A.; Amirkhanova, A.K. Catalytic synthesis of pyrazinamide from 2,5-dimethylpyrazine. Pharm. Chem. J. 1999, 33, 381-383. [CrossRef]

9. Bondareva, V.M.; Andrushkevich, T.V.; Paukshtis, E.A.; Paukshtis, N.A.; Budneva, A.A.; Parmon, V.N. Investigation of the reaction mechanism of methylpyrazine ammoxidation on vanadia-titania catalyst by FTIR in situ. J. Mol. Catal. A 2007, 269, 240-245. [CrossRef]

10. Bondareva, V.M.; Andrushkevich, T.V.; Lapina, O.B.; Vlasov, A.A.; Dovlitova, L.S.; Burgina, E.B. Ammoxidation of methylpyrazine over vanadium-titanium catalysts modified by alkali additives. React. Kinet. Catal. Lett. 2003, 78, 355-363. [CrossRef]

11. Manohar, B.J. Ammoxidation of 2-methylpyrazine to 2-cyanopyrazine over promoted VPO catalysts and alumina supported Sb-VPO catalyst. Chem. Pharmaceut. Res. 2012, 4, 2781-2788.

12. Srilaxmi, C; Lingaiah, N.; Hussain, A.; Sai Prasad, P.S.; Narayana, K.V.; Martin, A.; Lücke, B. In situ synthesis and ammoxidation activity of ammonium salt of molybdophosphoric acid on $\mathrm{VPO}_{4}$ catalysts. Catal. Commun . 2004, 5, 199-203.

13. Nagaraju, P.; Srilakshmi, C.; Nayeem Pasha, N.; Lingaiah, N.; Suryanarayana, I.; Prasad, P.S. Effect of P/Fe ratio on the structure and ammoxidation functionality of Fe-P-O catalysts. Appl. Catal. A 2008, 334, 10-19. [CrossRef]

14. Hong, C.; Li, Y. 2-Cyanopyrazine prepared from 2-methylpyrazine by catalytic ammoxidation on MoVPO catalyst. Chin. J. Chem. Eng. 2006, 14, 670-675. [CrossRef]

15. Srilakshmi, Ch.; Nagaraju, P.; Sreedhar, B.; Prasad, P.S.; Kalevaru, V.N.; Lücke, B.; Martin, A. Ammoxidation activity of in situ synthesized ammonium salt of molybdophosphoric acid on $\mathrm{VOPO}_{4}$ catalysts. Catal. Today 2009, 141, 337-343. [CrossRef]

16. Reddy, K.M.; Lingaiah, N.; Rao, P.S.N.; Nagaraju, P.; Prasad, P.S.; Suryanarayana, I. Studies on Ceria Supported Vanadium Incorporated Ammonium Salt of 12-Molybdophosphoric Acid Catalysts. Catal. Lett. 2009, 130, 154-160. [CrossRef]

17. Reddy, B.M.; Manohar, B.; Reddy, E.P.; Patil, K.S.; Rao, A.V.R. An improved process of ammoxidation for the preparation of 2-cyanopyrazine from 2-methylpyrazine using a vanadium-molybdenum catalyst in the presence of solvent. Patent IN 182185, 23 January 1999.

18. Alshammari, A.; Kalevaru, V.N.; Dhachapally, N.; Köckritz, A.; Bagabas, A.; Martin, A. Nanosize Gold Promoted Vanadium Oxide Catalysts for Ammoxidation of 2-Methylpyrazine to 2-Cyanopyrazine. Top. Catal. 2015, 58, 1062-1068. [CrossRef]

19. Forni, L.; Toscano, M.; Pollesel, P. TPD-TPR-MS mechanistic study of the ammoxidation of 2-methylpyrazine over Sb-V-Mn-O catalyst. J. Catal. 1991, 130, 392-402. [CrossRef]

20. Forni, L. Ammoxidation of 2-methylpyrazine over oxide catalysts. Appl. Catal. 1986, 20, 219-230. [CrossRef]

21. Dhachapally, N.; Kalevaru, V.N.; Radnik, J.; Martin, A. Tuning the surface composition of novel metal vanadates and effect on their catalytic performance. Chem. Commun. 2011, 47, 8394-8396. [CrossRef] [PubMed]

22. Dhachapally, N.; Kalevaru, V.N.; Brückner, A.; Martin, A. Metal vanadate catalysts for the ammoxidation of 2-methylpyrazine to 2-cyanopyrazine. Appl. Catal. A 2012, 443-444, 111-118. [CrossRef]

23. Martin, A.; Berndt, H.; Lücke, B.; Meisel, M. Reaction pathway of benzonitrile formation during toluene ammoxidation on vanadium phosphate catalysts. Top. Catal. 1996, 3, 377-386. [CrossRef] 
24. Dhachapally, N.; Kalevaru, V.N.; Martin, A. Effect of $\mathrm{Nb} / \mathrm{V}$ ratio on the catalytic properties of mixed $\mathrm{Nb}-\mathrm{V}$ oxides in the ammoxidation of 2-methylpyrazine to 2-cyanopyrazine. Catal. Sci. Technol. 2014, 4, 3306-3316. [CrossRef]

25. Radnik, J.; Dhachapally, N.; Kalevaru, V.N.; Sinev, I.; Grünert, W.; Martin, A. Impact of the outermost layer of various solid metal vanadate catalysts on ammoxidation of 2-methyl pyrazine to 2-cyanopyrazine. Catal. Commun. 2015, 71, 97-101. [CrossRef]

26. Dhachapally, N.; Kalevaru, V.N.; Martin, A. Catalyst, its preparation and use for the preparation of nitriles from alkyl aromatic or heteroaromatic compounds. EP 2428267 A1, 14 March 2012.

(c) 2016 by the authors; licensee MDPI, Basel, Switzerland. This article is an open access article distributed under the terms and conditions of the Creative Commons by Attribution (CC-BY) license (http:/ / creativecommons.org/licenses/by/4.0/). 